This document was prepared in conjunction with work accomplished under Contract No. DE-AC09-96SR18500 with the U.S. Department of Energy.

This work was prepared under an agreement with and funded by the U.S. Government. Neither the U. S. Government or its employees, nor any of its contractors, subcontractors or their employees, makes any express or implied: 1 . warranty or assumes any legal liability for the accuracy, completeness, or for the use or results of such use of any information, product, or process disclosed; or 2 . representation that such use or results of such use would not infringe privately owned rights; or 3 . endorsement or recommendation of any specifically identified commercial product, process, or service. Any views and opinions of authors expressed in this work do not necessarily state or reflect those of the United States Government, or its contractors, or subcontractors. 


\title{
Carbon Nanomaterials as Catalysts for Hydrogen Uptake and Release in $\mathrm{NaAlH}_{4}$
}

\author{
Polly A. Berseth, ${ }^{1}$ Andrew G. Harter, ${ }^{1}$ Ragaiy Zidan, ${ }^{* 1}$ Andreas Blomqvist ${ }^{2}$, C. Moysés
} Araújo $^{2}$, Ralph H. Scheicher ${ }^{2}$, Rajeev Ahuja ${ }^{2,3}$, and Puru Jena ${ }^{4}$

${ }^{1}$ Energy Security Directorate, Savannah River National Lab, P. O. Box A, Aiken, SC 29803, United States of America

${ }^{2}$ Condensed Matter Theory Group, Department of Physics and Materials Science, Uppsala University, Box 530, SE-751 21 Uppsala, Sweden

${ }^{3}$ Applied Materials Physics, Department of Materials Science and Engineering, Royal Institute of Technology, SE-100 44 Stockholm, Sweden

${ }^{4}$ Physics Department, Virginia Commonwealth University, Richmond, VA 23284, United States of America

\begin{abstract}
:
A synergistic approach involving experiment and first-principles theory not only shows that carbon nanostructures can be used as catalysts for hydrogen uptake and release in complex metal hydrides such as sodium alanate, $\mathrm{NaAlH}_{4}$, but also provides an unambiguous understanding of how the catalysts work. The stability of $\mathrm{NaAlH}_{4}$ originates from the charge transfer from $\mathrm{Na}$ to the $\mathrm{AlH}_{4}$ moiety, resulting in an ionic bond between $\mathrm{Na}^{+}$and $\mathrm{AlH}_{4}{ }^{-}$and a covalent bond between $\mathrm{Al}$ and $\mathrm{H}$. Interaction of $\mathrm{NaAlH}_{4}$ with an electro-negative substrate such as carbon fullerene or nanotube affects the ability of $\mathrm{Na}$ to donate its charge to $\mathrm{AlH}_{4}$, consequently weakening the $\mathrm{Al}-\mathrm{H}$ bond and causing hydrogen to desorb at lower temperatures as well as facilitating the absorption of $\mathrm{H}_{2}$ to reverse the dehydrogenation reaction. Ab initio molecular dynamics simulation further reveals the time evolution of the charge transfer process with hydrogen desorption occurring when the charge transfer is complete.
\end{abstract}

\section{Introduction:}

One key component of realizing the hydrogen economy for transportation applications is developing cost effective materials that can store and release hydrogen with large gravimetric and volumetric densities under moderate thermodynamic conditions $(1,2)$. One of the most promising classes of materials for hydrogen storage is complex hydrides such as alanates and borohydrides. Among these, sodium aluminum hydride $\left(\mathrm{NaAlH}_{4}\right)$ is the most widely studied material. The thermodynamics and kinetics of hydrogen uptake and release of these materials are such that catalysts are needed to improve the reaction rates. The pioneering work of Bogdanovich and Schwickardi demonstrated that $\mathrm{TiCl}_{3}$ acts as a catalyst to render sodium alanate $\left(\mathrm{NaAlH}_{4}\right)$ reversible and improve the hydrogen 
sorption behavior. This has led to optimism that alanates may be suitable materials for hydrogen storage (3).

Despite extensive research on $\mathrm{NaAlH}_{4}$ catalyzed with $\mathrm{TiCl}_{3}$ and other materials in the decade since $(4,5)$, a fundamental understanding of how the Ti catalyst works has not been possible (6-9). The presence of $\mathrm{NaCl}$ and traces of $\mathrm{Ti} / \mathrm{Al}$ alloys have been detected implying that the $\mathrm{TiCl}_{3}$ catalyst has taken part in a chemical reaction. It is widely believed that a fundamental understanding of how the catalyst works may help in the rational design of new catalysts for the alanates as well as for other complex hydrides (e.g. borohydrides and amides).

Several groups have investigated the use of carbon materials as possible catalysts for $\mathrm{NaAlH}_{4}$, and samples were almost exclusively ball milled (10-14). Four of these groups report that carbon materials are catalysts for the dehydrogenation and rehydrogenation of $\mathrm{NaAlH}_{4}$ (10-13). However, ball milling is known to degrade fragile carbon nanostructures $(15,16)$ and is known to introduce Fe contamination from the ball mill vial and/or balls $(17,18)$, and $\mathrm{Fe}$ is an excellent catalyst for dehydrogenation of $\mathrm{NaAlH}_{4}(19)$. When studying carbon materials as catalysts for $\mathrm{NaAlH}_{4}$, care must be taken in the preparation of samples. We were interested in investigating this property of carbon nanomaterials with sample preparation techniques which avoid introduction of metal contaminants and degradation of the carbon nanostructures. We used a solvent preparation technique to intimately mix the $\mathrm{NaAlH}_{4}$ and carbon without introducing metal contaminants.

In this paper we not only show that carbon nanostructures such as $\mathrm{C}_{60}$ fullerenes and nanotubes (CNT) can be used as catalysts for dehydrogenation and rehydrogenation of sodium alanate, but also provide a fundamental understanding of how these catalysts work. This has significance beyond just $\mathrm{NaAlH}_{4}$ and can apply to other complex metal hydride materials. $\mathrm{C}_{60}$ fullerene, carbon nanotubes, and graphene are models of zero, one, and two dimensional carbon nanostructures, and their chemistry can be manipulated by changing their curvature and dimensionality. Changes in curvature of CNT can also have catalytic effects due to localization/delocalization of electrons. Theoretical calculations show that the geometrical parameters of CNTs deviate from the values obtained from simple wrapping of a perfect hexagonal sheet. The lattice constant along the tube axis exhibits a slight shrinking. The radial breathing mode (RBM) frequency does not follow the usually assumed 1/d behavior and there is a general softening with the increase of curvature; thus the deviation from the expected behavior increases with increasing curvature. The lattice constant along the tube axis also exhibits a slight shrinking when compared to bulk graphite (20).

Our first-principles calculations show that the energies needed to remove a hydrogen atom from $\mathrm{NaAlH}_{4}$ supported on a $(5,0)$ carbon nanotube or $\mathrm{C}_{60}$ fullerene are significantly smaller than those in pure sodium alanate and are nearly the same as when $\mathrm{Ti}$ is substituted at the $\mathrm{Na}$ site in sodium alanate. Interestingly, no structural changes of 
the carbon nanostructures take place, and unlike $\mathrm{TiCl}_{3}$, the carbon nanotubes and fullerenes behave as true catalysts. The results can be explained in very simple terms by using the chemistry of the carbon substrates and that of the $\mathrm{NaAlH}_{4}$ cluster. Note that the $\mathrm{NaAlH}_{4}$ cluster is stabilized by the formation of the $\left(\mathrm{AlH}_{4}\right)^{-}$anion, charge balanced by having $\mathrm{Na}^{+}$in the cationic form. As $\mathrm{NaAlH}_{4}$ interacts with a substrate that is as electronegative as $\mathrm{AlH}_{4}$, the ability of $\mathrm{Na}$ to donate the electron to form the $\left(\mathrm{AlH}_{4}\right)^{-}$anion is compromised and hence the covalent bond between $\mathrm{Al}$ and $\mathrm{H}$ is weakened. This weakening of the metal-hydrogen bond leads to lowering of the hydrogen desorption energy and hence to improved kinetics. In the following we establish this picture through experiment and first principles calculations.

\section{Experimental results:}

Mixtures containing $\mathrm{NaAlH}_{4}$ with various types of carbon, including graphite, CNT of various diameters, and $\mathrm{C}_{60}$ were made using a ball mill free preparation method that prevents the degradation and creation of defect sites in the carbon materials (see supporting information for material preparation conditions). Titanium was added to one CNT preparation for comparison. The results of the hydrogen cycling screening test are summarized in Fig. 1 below. These results are from the second desorption cycle, as it is possible that residual solvent contributed to the first desorption cycle. The carbon samples all aid in the absorption of hydrogen, and as expected, pure $\mathrm{NaAlH}_{4}$ with no additives does not rehydride from the $\mathrm{NaH}$ product without addition of $\mathrm{Ti}$ or carbon. We found that $\mathrm{C}_{60}$ is the best carbon additive for $\mathrm{NaAlH}_{4}$, rehydriding $\mathrm{NaAlH}_{4}$ by $4.3 \mathrm{wt} \%$ over 8 hour's time.

Based on the initial screening study, we explored the $\mathrm{C}_{60}$ mixture in more detail. Sample preparation was repeated by a second individual using $\mathrm{C}_{60}$ from another source. To ensure that the effect was not due to unknown metal contamination, a $\mathrm{C}_{60}$ sample was evaluated by neutron activation analysis. A very small amount $\left(242: 1 \mathrm{C}_{60}: \mathrm{Cu}\right)$ of $\mathrm{Cu}$ contaminant was found, and is not expected to play a role in catalysis due to the trace concentration. To verify this, a control sample containing $4 \mathrm{~mol} \% \mathrm{CuCl}$ in $\mathrm{NaAlH}_{4}$ was tested and it rehydrides to $c a$. half the amount that the $\mathrm{C}_{60}$ mixture does, confirming the catalytic activity is due to $\mathrm{C}_{60}$. Fig. 2 below shows the second desorption cycle for two $\mathrm{C}_{60}$ samples. The desorption temperature is lowered to ca. $130{ }^{\circ} \mathrm{C}$ by addition of $\mathrm{C}_{60}$ (from ca. $180{ }^{\circ} \mathrm{C}$ in uncatalyzed $\mathrm{NaAlH}_{4}$ ). The sample with a longer time $\mathrm{H}_{2}$ absorption cycle releases a higher weight percent of $\mathrm{H}_{2}$.

We do see differences in the dehydrogenation temperature of the $\mathrm{NaAlH}_{4}$ based on the diameter of the CNT added to the material. Figure 3 shows the thermo-gravimetric analysis (TGA) data for the dehydrogenation of $\mathrm{NaAlH}_{4}$ combined with $8 \mathrm{~nm}, 10-20 \mathrm{~nm}$, or $50 \mathrm{~nm} \mathrm{CNT}$. We can see that the inflection point for the second desorption step varies by CNT diameter with $\sim 231{ }^{\circ} \mathrm{C}$ for the $10-20 \mathrm{~nm} \mathrm{CNT}, \sim 243{ }^{\circ} \mathrm{C}$ for the $8 \mathrm{~nm}$ CNT next, and $\sim 251{ }^{\circ} \mathrm{C}$ evidenced by the $50 \mathrm{~nm}$ CNT mixture. The tube diameter plays a less obvious role in the first desorption step, where the largest and smallest diameter CNT 
give most of their $\mathrm{H}_{2}$ at the same temperature. Bulk quantities of CNT contain tubes with a distribution of diameters, and as the diameters span less than $100 \mathrm{~nm}$ in total, we await the availability of bulk CNT samples with very narrow diameter distributions to explore this temperature dependence further.

The mechanism for $\mathrm{H}_{2}$ absorption aided by carbon materials is of great interest. Carbon nanotubes are graphitic carbon sheets rolled into tubes, and it is possible that the accelerated absorption relative to flat graphite particles is due in part to the changes in the $\pi$ - and $\sigma$-bonding orbitals that the $\mathrm{H}_{2}$ molecules interact with on the surface of the material. The fullerene material $\mathrm{C}_{60}$ is a $0.7 \mathrm{~nm}$ sphere made of graphitic carbon and has increased curvature relative to the $8-50 \mathrm{~nm}$ carbon nanotubes, and exhibits the strongest catalytic affect on $\mathrm{NaAlH}_{4}$, suggesting the curvature of the carbon material is important to the function. Note that carbon nanotubes, even after cleaning, generally contain small amounts of residual catalyst material used in their synthesis (e.g. Fe, Co, or Ni), and the $\mathrm{C}_{60}$ material contains trace amounts of $\mathrm{Cu}$. Ab initio modeling was undertaken to further understand the interactions taking place between $\mathrm{NaAlH}_{4}$ and the carbon nanomaterials.

\section{Modeling results:}

To study the interaction of sodium alanate with the carbon nano-structures (fullerenes, nanotubes, and graphene) we modeled sodium alanate with a single formula unit, namely a $\mathrm{NaAlH}_{4}$ cluster. This approach is supported by earlier theoretical and experimental results where it has been demonstrated that very small clusters can mimic the properties of their crystals if the latter are characterized by strong covalent or ionic bonds such as those in TiN (21), $\mathrm{NaCl}(22), \mathrm{Sb}_{2} \mathrm{O}_{5}(23)$, and $\mathrm{W}_{2} \mathrm{O}_{3}$ (24). The calculated $\mathrm{Al}-\mathrm{H}$ bond lengths of 1.6 to $1.7 \AA$ in $\mathrm{NaAlH}_{4}$ cluster agree very well with that in the crystal, namely $1.64 \AA$. In addition, the energy necessary to remove one $\mathrm{H}$ atom from $\mathrm{NaAlH}_{4}$ cluster is $3.8 \mathrm{eV}$ while that from its crystal is $4.0 \mathrm{eV}(25,26)$. Thus, a $\mathrm{NaAlH}_{4}$ cluster possesses the essential properties of the sodium alanate crystal and may serve as a model when calculating the properties of sodium alanate interacting with carbon nano-structures.

We have considered zero-, one-, and two-dimensional carbon nano-materials, namely $\mathrm{C}_{60}$, single-walled carbon nanotubes of $(5,0),(4,4),(5,5)$, and $(8,0)$ type, and graphene. The diameters of the $(5,0),(4,4),(5,5)$, and $(8,0)$ nanotubes are respectively $3.92,5.43,6.78$, and $6.27 \AA$. The $\mathrm{NaAlH}_{4}$ cluster was found to preferably bind with the $\mathrm{Na}$ atom facing towards the carbon substrates. In Fig. 4 we provide the equilibrium geometry of the $\mathrm{NaAlH}_{4}$ cluster supported on the $(5,0)$ carbon nanotube $(\mathrm{CNT}), \mathrm{C}_{60}$ fullerene and graphene. The binding energies of the $\mathrm{NaAlH}_{4}$ cluster to these structures are very small, namely 36,68 , and $93 \mathrm{meV}$ for the $(5,0)$ nanotube, $\mathrm{C}_{60}$ fullerene, and graphene respectively. The distance between the $\mathrm{Na}$ atom and the carbon substrate is of the order of 2.3 to $2.4 \AA$. The distances between $\mathrm{Na}$ and $\mathrm{Al}$ and $\mathrm{Al}$ and $\mathrm{H}$ are respectively $2.8 \AA$ and 1.6 to $1.7 \AA$ in all these supports and are almost identical with the corresponding values in the isolated $\mathrm{NaAlH}_{4}$ cluster. The near equality of these bond distances and the low binding energies of the $\mathrm{NaAlH}_{4}$ cluster with the various carbon nanostructures indicate 
that they do not chemically react, a property characteristic of a true catalyst.

The substrates, on the other hand, have a dramatic effect on the hydrogen removal energy. These are calculated using the equation:

$\Delta \mathrm{E}=\mathrm{E}\left(\mathrm{CS}: \mathrm{NaAlH}_{3}\right)+\mathrm{E}(\mathrm{H})-\mathrm{E}\left(\mathrm{CS}: \mathrm{NaAlH}_{4}\right)$.

Here CS stands for a given carbon substrate (nanotube, fullerene, or graphene). The calculations of the removal energies require optimizing the geometry of $\mathrm{NaAlH}_{3}$ interacting with various nanostructures. The results are given in Fig. 4. Note that it costs $3.8 \mathrm{eV}$ to remove a $\mathrm{H}$ atom from an isolated $\mathrm{NaAlH}_{4}$ cluster while it costs only $2.0 \mathrm{eV}$ to remove the $\mathrm{H}$ atom when the $\mathrm{NaAlH}_{4}$ cluster is supported on a $(5,0)$ CNT. This is nearly same as that when $\mathrm{Ti}$ replaces the $\mathrm{Na}$ atom in a $\mathrm{NaAlH}_{4}$ crystal. We also note from Fig. 4 that the hydrogen removal energy from $\mathrm{NaAlH}_{4}$ supported on graphene is high, namely $3.60 \mathrm{eV}$ and that it varies between 2.95 to $3.07 \mathrm{eV}$ in $(4,4),(5,5)$, and $(8,0)$ nanotubes. For the $\mathrm{C}_{60}$ fullerene, the hydrogen removal energy is about $2.85 \mathrm{eV}$.

To determine the origin of the variation of the hydrogen removal energy from $\mathrm{NaAlH}_{4}$ supported on various carbon nano-structures, we have calculated the electron affinities of these structures, shown in Fig. 4. The electron affinity is found to depend upon the curvature of the substrate and it increases with increasing curvature. In addition, as the electron affinity of the substrate decreases, the energy to remove the hydrogen atom increases. This behavior can be very simply explained by studying the stabilities of $\mathrm{AlH}_{\mathrm{n}}$, $\mathrm{AlH}_{\mathrm{n}}{ }^{-}$, and $\mathrm{NaAlH}_{\mathrm{n}}$ clusters $(\mathrm{n}=1-4)$ as a function of number of $\mathrm{H}$ atoms. In Fig. 5 we plot these energy gains calculated using the formula,

$$
\begin{aligned}
& \Delta \mathrm{E}_{1}=\mathrm{E}\left(\mathrm{AlH}_{\mathrm{n}-1}\right)+\mathrm{E}(\mathrm{H})-\mathrm{E}\left(\mathrm{AlH}_{\mathrm{n}}\right) \\
& \Delta \mathrm{E}_{2}=\mathrm{E}\left(\mathrm{AlH} \mathrm{n}^{-}{ }^{-}\right)+\mathrm{E}(\mathrm{H})-\mathrm{E}\left(\mathrm{AlH}_{\mathrm{n}}{ }^{-}\right) \\
& \Delta \mathrm{E}_{3}=\mathrm{E}\left(\mathrm{NaAlH}_{\mathrm{n}-1}\right)+\mathrm{E}(\mathrm{H})-\mathrm{E}\left(\mathrm{NaAlH}_{\mathrm{n}}\right)
\end{aligned}
$$

It is clear that among neutral $\mathrm{AlH}_{\mathrm{n}}$ clusters, $\mathrm{AlH}_{3}$ is the most stable cluster and $\mathrm{AlH}_{4}$ is unstable against dissociation into $\mathrm{AlH}_{2}+\mathrm{H}_{2}$. This is in agreement with previous calculations (27). However, $\mathrm{AlH}_{4}$ cluster can be stabilized by adding an extra electron and $\mathrm{AlH}_{4}{ }^{-}$is the most stable species in the $\mathrm{AlH}_{n}{ }^{-}$cluster series. Hence, the stability of $\mathrm{NaAlH}_{4}$ cluster is governed by the charge transfer from $\mathrm{Na}$ to $\mathrm{AlH}_{4}$ transforming the former into a cation and the latter into an anion. This can be further seen by comparing the energy gain in adding $\mathrm{H}$ atoms, one at a time, to a $\mathrm{NaAlH}_{n}$ cluster. We see from Fig. 5 that the energy gained in adding one $\mathrm{H}$ atom to $\mathrm{AlH}_{3}{ }^{-}$is identical with that when added to the $\mathrm{NaAlH}_{3}$ cluster. This is further evidence that $\mathrm{Na}$ in $\mathrm{NaAlH}_{4}$ remains in a +1 charge state. For $\mathrm{NaAlH}_{n}$ clusters with $\mathrm{n}<4$, the energy gains are close to those in $\mathrm{AlH}_{\mathrm{n}}{ }^{-}$clusters, indicating that $\mathrm{Na}$ transfers partial charge to the $\mathrm{AlH}_{\mathrm{n}}$ moiety in all these cases.

Thus, the way to reduce the bond strength between $\mathrm{Al}$ and $\mathrm{H}$ in $\mathrm{NaAlH}_{4}$ would be to 
introduce a competitor for the charge donation from the $\mathrm{Na}$ atom. This can be realized in the form of an electro-negative substrate on which $\mathrm{NaAlH}_{4}$ is supported. In this case, the $\mathrm{Na}$ atom could have its electron contributed to the substrate or to the $\mathrm{AlH}_{4}$ unit or have it delocalized and shared by both. Situations involving the electron being transferred elsewhere than the $\mathrm{AlH}_{4}$ unit will result in a weakening of the $\mathrm{Al}-\mathrm{H}$ bond and lead to the lowering of the hydrogen desorption energy. The electron affinity of the substrate thus becomes intimately connected with the hydrogen desorption process, since the larger the electron affinity of the substrate, the greater is the probability of $\mathrm{Na}$ to donate its electron to the substrate.

The plot of the electron affinity of the various carbon nano-structures vs the hydrogen removal energy in Fig. 4 is best fitted by a parabola. Note that the hydrogen removal energy decreases as the electron affinity of the substrate increases. This relationship may be understood as follows. Once the hydrogen atom has left the $\mathrm{NaAlH}_{4}$ cluster, the remaining $\mathrm{NaAlH}_{3}$ unit can transfer charge to the carbon support and thus bring the total energy of the system to a lower level. The amount by which the energy can be lowered depends on two factors: (i) the electron affinity of the charge-receiving carbon nanomaterial, and (ii) the amount of charge actually being transferred from the $\mathrm{NaAlH}_{3}$ molecule. The latter is determined by the cost of energy to remove a charge $\mathrm{q}$ from $\mathrm{NaAlH}_{3}$ and the gain in energy due to the carbon nanomaterial accepting this charge. The difference between these two energy terms corresponds to the amount by which the system can actually lower its total energy. Hence, the $\mathrm{q}$ for which this difference reaches its maximum is the charge that will be transferred. This resulting energy gain is, to a good approximation, proportional to the product of charge and electron affinity as long as the transferred charge amount is comparatively small $(\mathrm{q}<1 \mathrm{e})$. As the amount by which the final state lowers its energy directly affects the hydrogen removal energy, we find that the decrease of the latter is indeed proportional to the product of transferred charge and electron affinity (see the inset of Fig. 4).

To arrive at a complete explanation as to how much the hydrogen removal energy is lowered in each case one also needs to take into account the Coulomb interaction which results between the charged $\mathrm{NaAlH}_{3}$ molecule and the carbon nanomaterial after the charge transfer has taken place between the two. If this interaction energy is taken into account together with the above described lowering of the total energy from the electron affinity, one arrives at the correct quantitative description of the mechanism that leads to the lowering of the hydrogen removal energy.

In addition to these zero-temperature binding energy calculations, we have also carried out $a b$ initio molecular dynamics studies at room temperature to study the time for $\mathrm{H}$ desorption as well as the evolution of the charge transfer process. The total simulation time was 3 ps with one time-step comprising 1 fs. Interestingly, we found that the reduction in hydrogen binding energy is sufficiently large so that dynamic effects can lead to a breakup with one hydrogen atom dissociating from the $\mathrm{NaAlH}_{4}$ molecular cluster after only $0.5 \mathrm{ps}$ simulation time for the $(5,0) \mathrm{CNT}$, and 0.4 ps for $(8,0)$ and $(5,5)$ 
CNT. It thus appears from our ab initio studies that the electronegative properties of CNTs and fullerenes can indeed lead to a sufficient reduction in hydrogen binding energies in sodium alanate, so that they can act as efficient catalysts for hydrogen removal, even at room temperature.

We have carried out a careful analysis of the charge transfer accompanying the dynamic $\mathrm{H}$-removal by performing Bader analysis at selected snapshots in the molecular dynamics simulation. In Fig. 6, we plot the total transferred charge from the $\mathrm{NaAlH}_{4}$ cluster as a function of time. The time axis has been arranged so that the H-removal event essentially coincides with $\mathrm{t}=0$. As it can be seen from the graph, the charge, due to dynamical effects, is continuously fluctuating between the CNT and the $\mathrm{NaAlH}_{4}$ cluster until a sudden charge transfer occurs when the hydrogen atom is departing.

\section{Conclusion:}

Our experimental and theoretical studies were conducted in concert to examine the interaction of sodium alanate with carbon nanostructures (fullerenes, nanotubes and graphene). We have shown that our results generally concur, providing insight into the interaction of $\mathrm{NaAlH}_{4}$ with nano-structured carbon surfaces. We have shown that carbon nanostructures, traditionally thought of as hydrogen storage materials, can in fact be used as catalysts for hydrogenation/dehydrogenation of sodium alanate, $\mathrm{NaAlH}_{4}$. We theorized that varying the diameters of the CNT's, and thereby varying their curvature, allows one to control their catalytic effect due to localization/delocalization of electrons. We have indeed shown that there are differences in the dehydrogenation temperature of the $\mathrm{NaAlH}_{4}$ based on the diameter of the CNT added to the material - consistent with our assumption. $\mathrm{C}_{60}$ materials were found to be the best carbon additive for $\mathrm{NaAlH}_{4}$, rehydriding $\mathrm{NaAlH}_{4}$ by $4.3 \mathrm{wt} \%$ over 8 hour's time. We suspect that a contributing factor to the performance of the $\mathrm{C}_{60}$ is it's dispersiblity. The $\mathrm{C}_{60}$ molecules likely have their entire surface available for interaction with $\mathrm{NaAlH}_{4}$. Graphite particles will only have the particle faces exposed to $\mathrm{NaAlH}_{4}$, and CNTs are known to agglomerate and likely are bundled together, lowering the surface available to $\mathrm{NaAlH}_{4}$. Experiments exploring the catalytic effect of carbon nanomaterials on other complex metal hydrides, e.g. borohydrides, are planned.

Using density functional theory and generalized gradient approximation for exchange and correlation we have shown that the electron affinity of the substrate is intimately connected with the hydrogen sorption mechanism. The larger the electron affinity of the substrate the greater is the probability of $\mathrm{Na}$ donating its electron to the substrate. The substrate was found to have a dramatic effect on the hydrogen removal energy. Experimentally we see that the curvature of the nanostructures plays a significant role in this process and $\mathrm{C}_{60}$ fullerene is a better catalyst than the nanotubes. Theory further shows that $(5,0)$ CNT may even be a better catalyst than $\mathrm{C}_{60}$ fullerene in the dehydrogenation of sodium alanate. 


\section{Acknowledgements:}

Funding was provided by a grant from the U.S. Department of Energy, Office of Basic Energy Science. P.A.B, A.G.H., and R. Z. would like to thank Dr. Joshua Gray for providing helpful assistance with Sievert's measurements. C.M.A., A.B., R.H.S., and R.A. gratefully acknowledge STINT, VR, FUTURA, Göran Gustafsson Stiftelse, and Wenner-Gren Stiftelserna for financial support, as well as SNIC and UPPMAX for providing computing time.

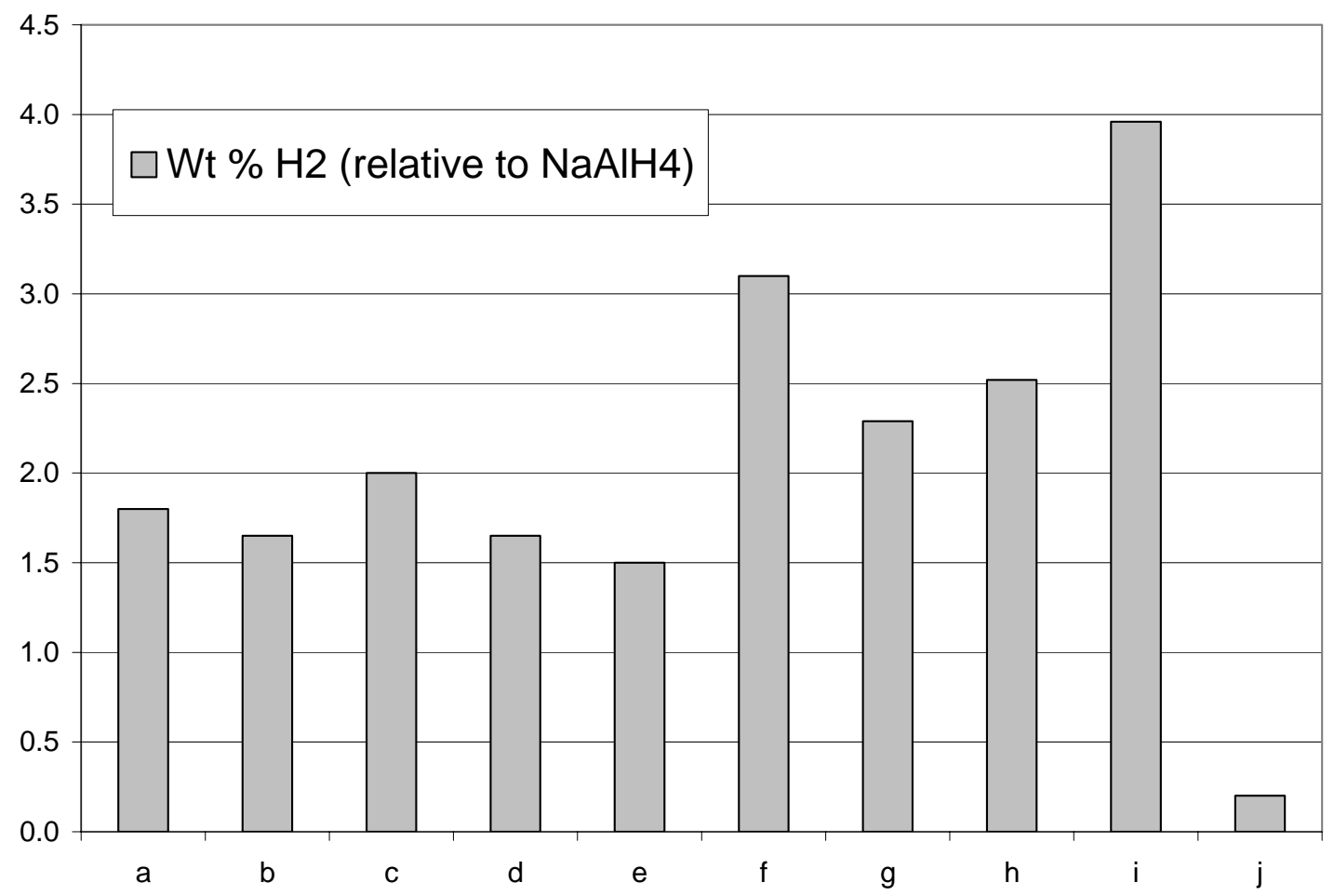

Fig. 1. Screening study results of $\mathrm{NaAlH}_{4} /$ carbon mixtures. Samples a-f and j were heated up to $280^{\circ} \mathrm{C}$ for 3 hours, and the previous absorption step was performed at $\sim 2.1 \times 10^{7} \mathrm{~Pa}$ $\mathrm{H}_{2}$ and $150{ }^{\circ} \mathrm{C}$. Samples g-i were heated to $350{ }^{\circ} \mathrm{C}$ for 3 hours, and the previous absorption step was performed at $\sim 1.2 \times 10^{7} \mathrm{~Pa} \mathrm{H}_{2}$ and $150{ }^{\circ} \mathrm{C}$. Sample key: a) $8 \mathrm{~nm}$ CNT, b) 10-20 nm CNT, c)10-20 nm CNT with 4 mol \% Ti, d) $50 \mathrm{~nm}$ CNT, e) graphite, f) $\left.\left.\mathrm{C}_{60}[1] \mathrm{g}\right) \mathrm{C}_{60}[2] \mathrm{h}\right) \mathrm{C}_{60}[3]$, i) control no carbon, ball mill $4 \mathrm{~mol} \% \mathrm{TiCl}_{3}$, j) control no carbon. 


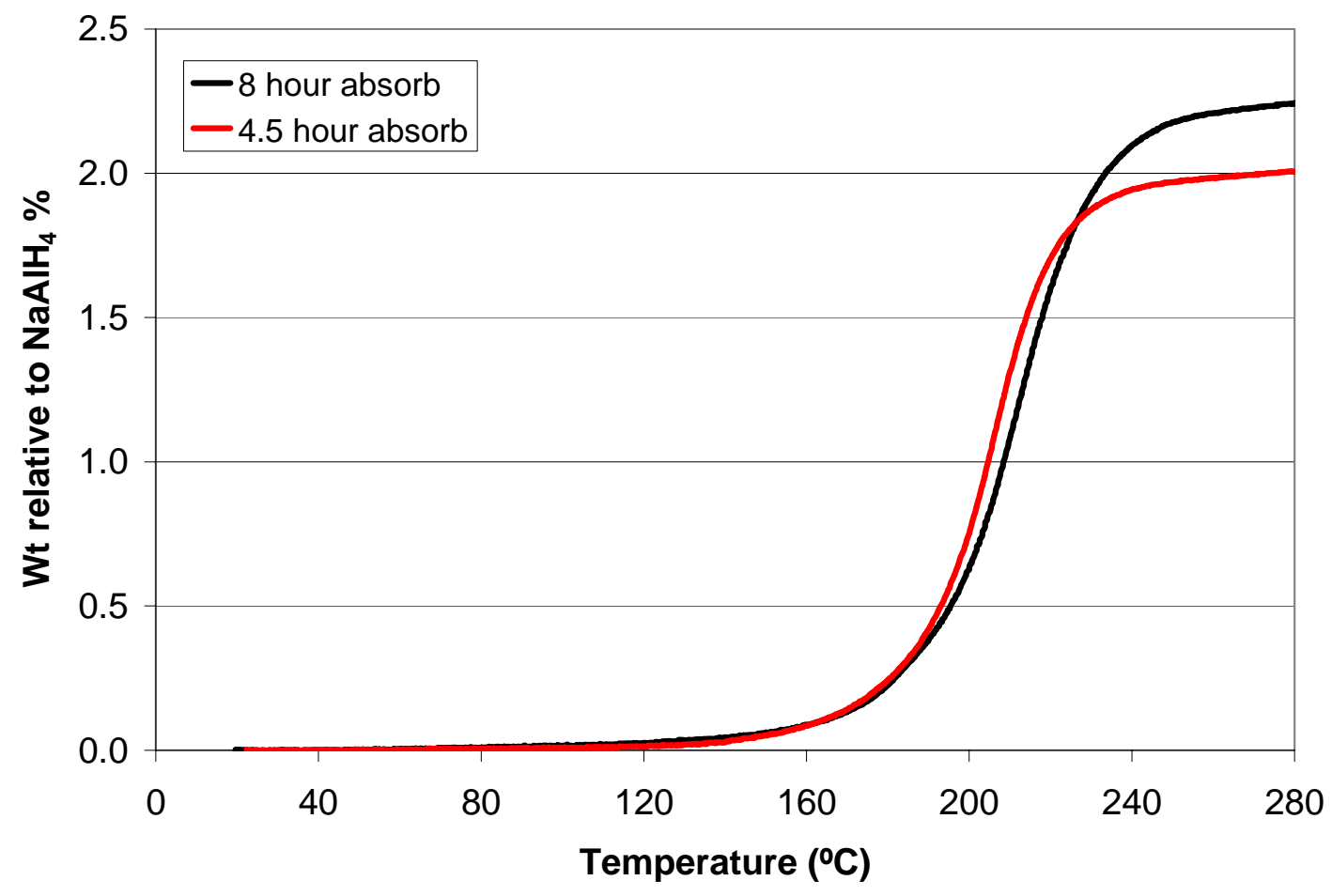

Fig. 2. Second desorption of $\mathrm{C}_{60} / \mathrm{NaAlH}_{4}$ mixtures. Samples were absorbed with $\sim 1.2 \mathrm{x}$ $10^{7} \mathrm{~Pa} \mathrm{H}_{2}$ for 8 and 4.5 hours, respectively. 


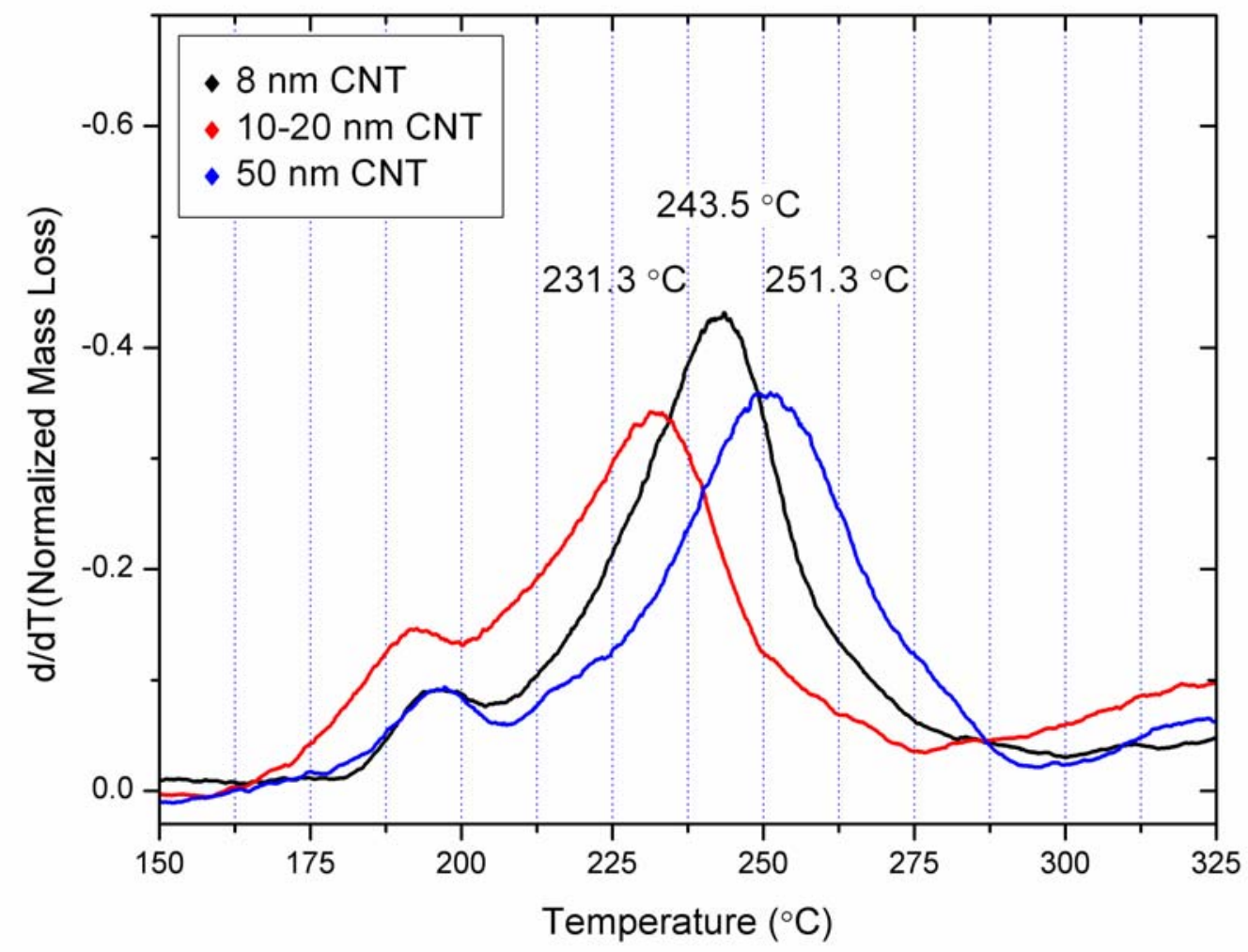

Fig. 3. TGA derivitave of $\mathrm{NaAlH}_{4} / \mathrm{CNT}$ mixtures for three different diameters of $\mathrm{CNT}$. 


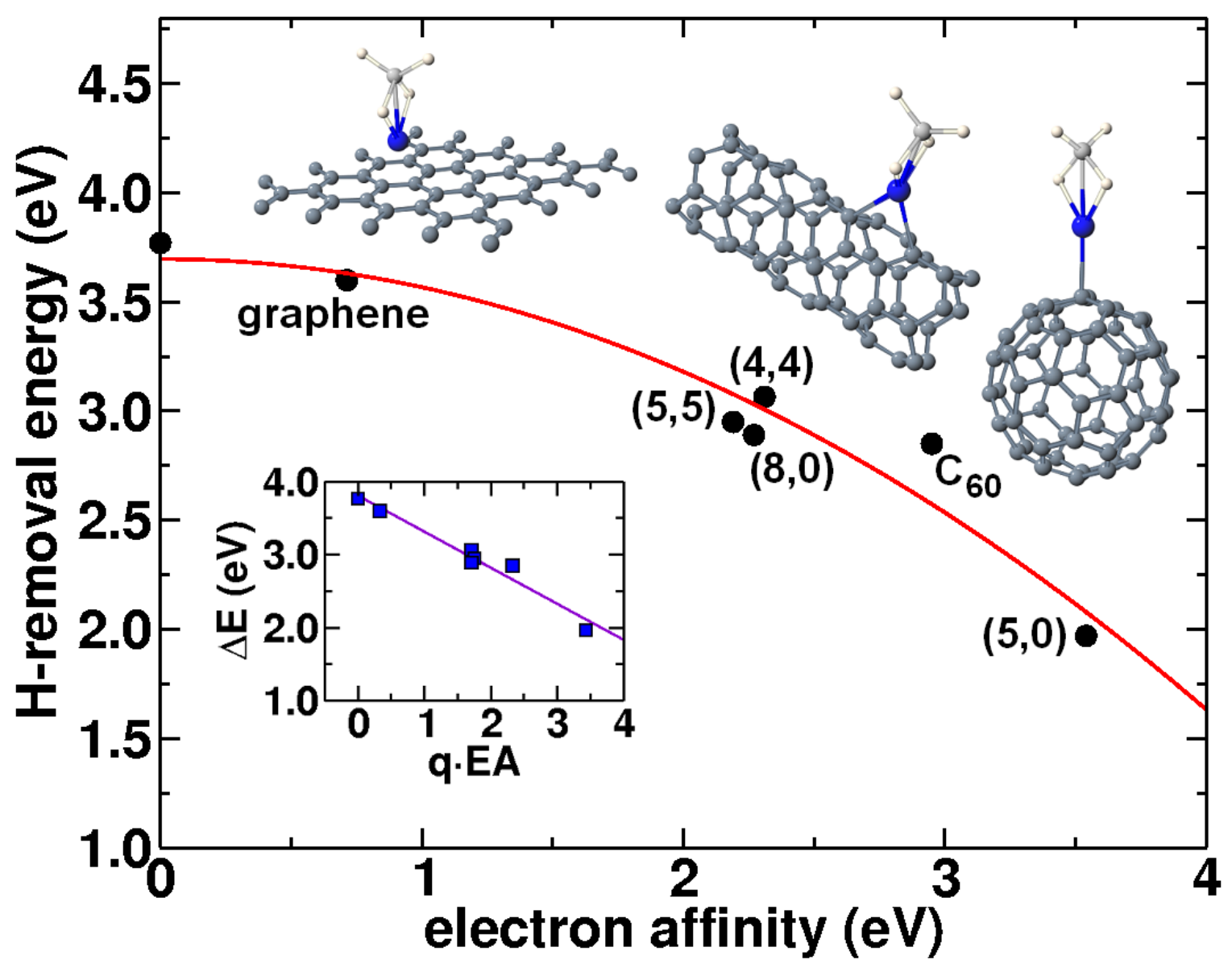

Fig. 4 Black circles are ab initio results for H-removal energy as a function of electron affinity (EA) of the carbon substrate. The red curve is a fit of the data with a quadratic function. The inset below the red curve shows the linear relationship between the $\mathrm{H}$ removal energy $(\Delta \mathrm{E})$ to the product of transferred charge $(\mathrm{q})$ and EA. The inset above the red curve displays the equilibrium configurations for $\mathrm{NaAlH}_{4}$ interacting with a graphene sheet, $(5,0)$ zigzag carbon nanotube, and fullerene. $\mathrm{Na}$ atom is shown as a blue sphere, $\mathrm{Al}$ in light gray, $\mathrm{C}$ in dark gray, and $\mathrm{H}$ in white. 


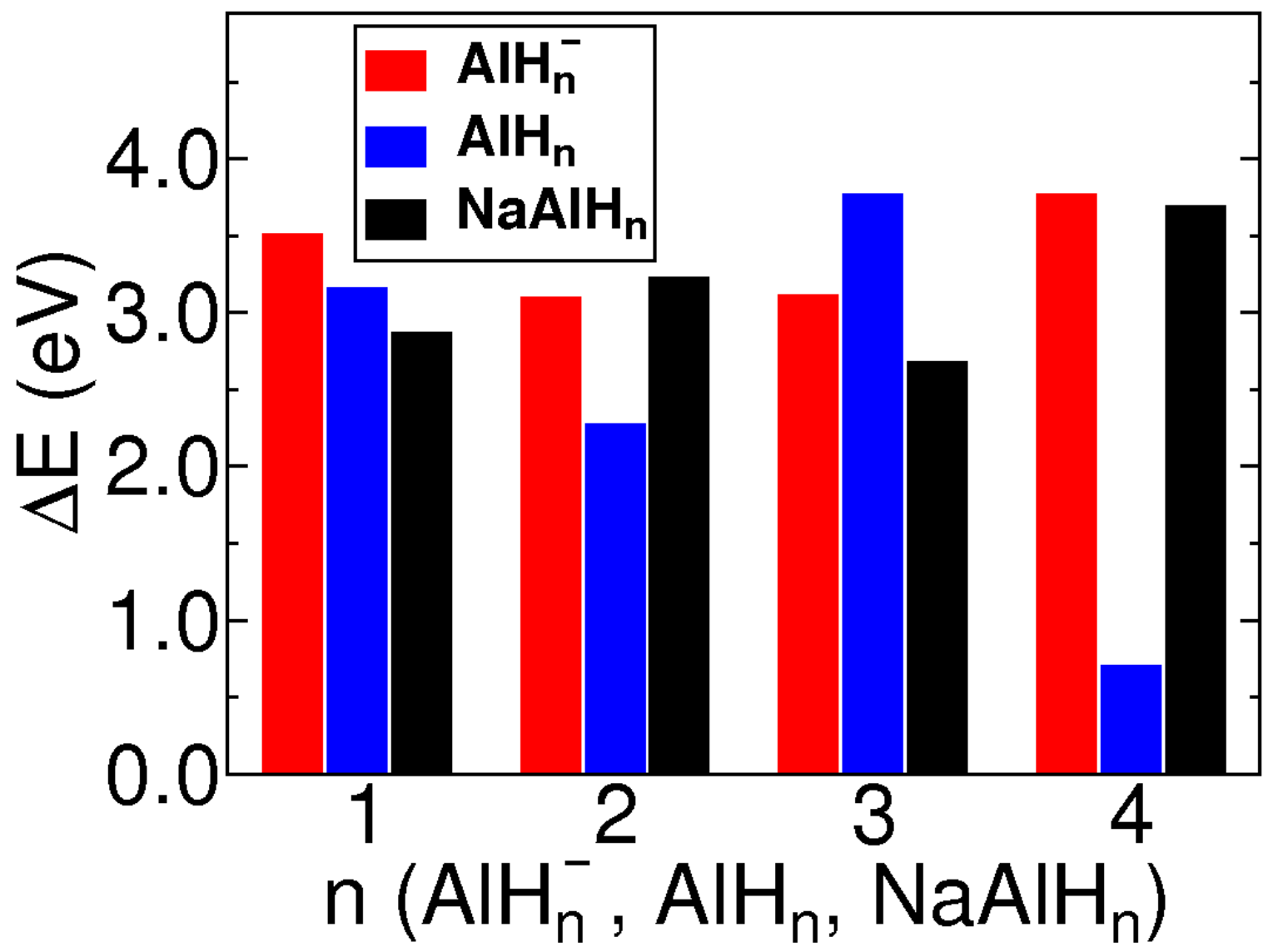

Fig. 5 The energy gain in adding a hydrogen atom to $\mathrm{AlH}_{\mathrm{n}-1}{ }^{-}, \mathrm{AlH}_{\mathrm{n}-1}$, and $\mathrm{NaAlH}_{\mathrm{n}-1}$ clusters.

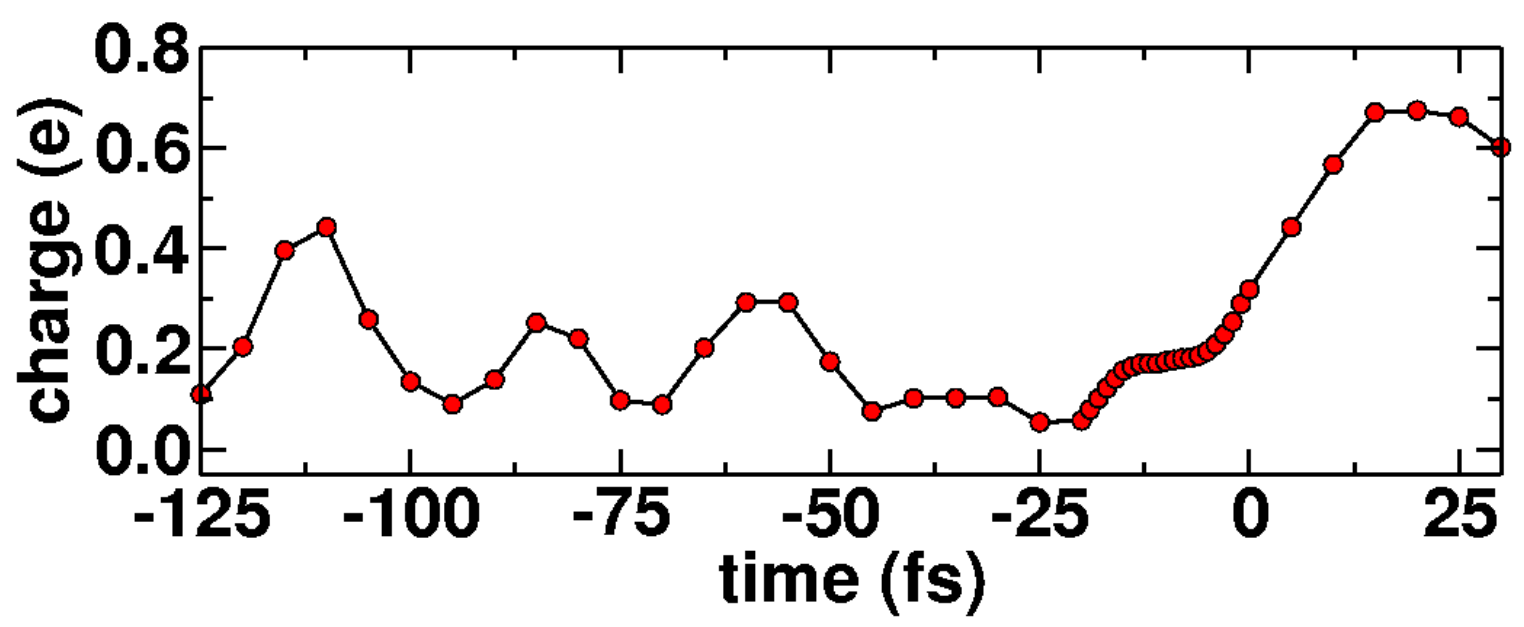

Fig. 6 Charge of the $\mathrm{NaAlH}_{4}$ molecule as a function of time. The release of one hydrogen occurs at approximately $\mathrm{t}=0$. 


\section{References:}

1. S. Satyapal, J. Petrovic, C. Read, G. Thomas, G. Ordaz, Cat. Today 120, 246 (2007).

2. D. K. Ross, Vacuum 80, 1084 (2006).

3. B. Bogdanovic, M. Schwickardi, J. Alloys Compd. 253-254, 1 (1997).

4. B. Sakintuna, F. Lamari-Darkrim, M. Hirscher, Int. J. Hydrogen Energy 32, 1121 (2007).

5. G. Sandrock, K. Gross, G. Thomas, J. Alloys Compd. 339, 299 (2002).

6. C. P. Balde, H. A. Stil, A. M. J. vanderEerden, K. P. deJong, J. H. Bitter, J. Phys. Chem. C 111, 2797 (2007).

7. A. G. Haiduc, H. A. Stil, M. A. Schwarz, P. Paulus, J. J. C. Geerlings, J. Alloys Compd. 393, 252 (2005).

8. E. H. Majzoub, K. J. Gross, J. Alloys Compd.356-357, 363 (2003).

9. A. Léon et al., J. Alloys Compd. 414, 190 (2006).

10. C. Cento et al., J. Alloys Compd. 437, 360 (2007).

11. A. L. Dehouche, L.; Grimard, N.; Goyette, J.; Chahine, R., Nanotechnology 16, 402 (2005).

12. A. Zaluska, L. Zaluski, J. O. Strom-Olsen, J. Alloys Compd. 298, 125 (2000).

13. D. Pukazhselvan, B. K. Gupta, A. Srivastava, O. N. Srivastava, J. Alloys Compd. 403, 312 (2005).

14. J. Wang, A. D. Ebner, J. A. Ritter, J. Phys. Chem. B 110, 17353 (2006).

15. Z. Tao, H. Geng, K. Yu, Z. Yang, Y. Wang, Mat. Lett. 58, 3410 (2004).

16. N. Pierard et al., Carbon 42, 1691 (2004).

17. V. P. Balema, A. O. Pecharsky, V. K. Pecharsky, J. Alloys Compd. 307, 184 (2000).

18. V. P. Balema, V. K. Pecharsky, K. W. Dennis, J. Alloys Compd. 313, 69 (2000).

19. B. Bogdanovic, R. A. Brand, A. Marjanovic, M. Schwickardi, J. Tolle, J. Alloys Compd. 302, 36 (2000).

20. J. Kurti, Zolyomi, V., Kertesz, M., Sun, G., New J. Phys. 5, 1 (2003).

21. Z. Y. Chen, and A. W. Castleman, Jr., J. Chem. Phys. 98, 231 (1993).

22. P. Xia, L. Bloomfield, Phys. Rev. Lett. 70, 1779 (1993).

23. B. V. Reddy, P. Jena: Chem. Phys. Lett. 288, 253 (1998).

24. Q. Sun, B. K. Rao, P. Jena, P. Stolic, G. Gantefor, A. W. Castleman, J. Chem. Phys. 121, 9417 (2004).

25. C. Moysés Araújo, R. Ahuja, J. M. Osorio Guillén, P. Jena, Appl. Phys. Lett. 86, 251913 (2005).

26. C. Moysés Araújo, S. Li, R. Ahuja, P. Jena, Phys. Rev. B 72, 165101 (2005).

27. B. K. Rao, P. Jena, S. Burkart, G. Ganteför, and G. Seifert: Phys. Rev. Lett. 86, 692 (2001). 


\section{Supporting Information:}

\section{Sample preparation:}

Samples were prepared by combining $\mathrm{NaAlH}_{4}$ and carbon in a Schlenk flask or in a vial within an Argon-filled glove box. Tetrahydrofuran (THF) was added and the mixture stirred with a Teflon coated magnetic stir bar for 30-60 minutes. The solvent was removed under reduced pressure and the remaining solids collected. Titanium catalyst was added to one sample by addition of $4 \mathrm{~mol} \%$ titanium (IV) tert-butoxide to the THF mixture. The butoxide functional groups react with the hydride to form alcohol which is removed with the other solvent, leaving a powdered product. This synthesis technique was used for two reasons: (i) to avoid adding metallic contaminants from mixing by ball milling in stainless steel vials and (ii) $\mathrm{NaAlH}_{4}$ is soluble in THF and creates a material in which the $\mathrm{NaAlH}_{4}$ is finely dispersed, coating and intimately mixing with the carbon additives.

A control sample was made of $\mathrm{NaAlH}_{4}$ mixed with 4 mol percent $\mathrm{TiCl}_{3}$. The mixture was milled for 60 minutes in a Spex 8000 ball mill. The vial volume is $65 \mathrm{~mL}$, and two 12.7 $\mathrm{mm}$ and four $6.4 \mathrm{~mm}$ balls were used for mixing. Mixture components and balls were loaded into ball mill vials under an inert atmosphere (argon gas).

Thermogravimetric analysis was performed on a PerkinElmer Pyris 1 instrument enclosed in an Argon filled glove box. Samples were heated at $2{ }^{\circ} \mathrm{C}$ per minute to $400{ }^{\circ} \mathrm{C}$.

Neutron activation analysis (NAA) was performed on commercially purchased $\mathrm{C}_{60}$ (Sigma-Aldrich 98\%). NIST-traceable standards of $\mathrm{Ti}$ and $\mathrm{Cu}$ were used for analysis. These two metals were chosen as Ti is known to be an excellent catalyst for $\mathrm{NaAlH}_{4}$, and $\mathrm{C}_{60}$ is prepared by the carbon arc method in which $\mathrm{Cu}$ electrode connections are common. A Cf-252 source was used, and samples were analyzed for $n$-induced gamma emissions. No measurable Ti activation products were seen. A small amount of $\mathrm{Cu}-66$ was detected, $3.61 \times 10^{2} \mu \mathrm{g} / \mathrm{g}\left(242: 1 \mathrm{C}_{60}: \mathrm{Cu}\right)$.

Chemicals were used as provided by the supplier and are listed by supplier as follows. Acros: THF (anhydrous, 99.9\%, inhibitor-free). Albemarle: $\mathrm{NaAlH}_{4}$. Alfa Aesar: $\mathrm{C}_{60}$ (98\%). Cheap Tubes, Inc.: carbon nanotubes, all diameters. Sigma-Aldrich: $\mathrm{TiCl}_{3}$ (99.999\%), $\mathrm{C}_{60}$ (98\%), THF (anhydrous, $\geq 99.9 \%$, inhibitor-free), titanium(IV) tertbutoxide $(97 \%)$.

\section{Hydrogen desorption and absorption:}

Measurements were made on two Sievert's apparatii. One is a custom constant volume Sievert's apparatus. Dehydrogenation experiments were started at $0 \mathrm{~Pa}$, and the pressure increased to approximately $2.8 \times 10^{5} \mathrm{~Pa}$ during the course of the reaction as the samples were heated to $280{ }^{\circ} \mathrm{C}$ for 3 hours. The hydrogenation experiments were conducted at 
$150{ }^{\circ} \mathrm{C}$ for 3 hours (or longer) starting with an approximately $2.1 \times 10^{7} \mathrm{~Pa} \mathrm{H}_{2}$ gas overpressure. Samples were dehydrogenated at least twice, with a hydrogenation cycle between.

The second Sievert's instrument is a Hy-Energy PCT Pro 2000. Dehydrogenation experiments were run at approximately $1.0 \times 10^{5} \mathrm{~Pa}$ as the samples were heated to $350{ }^{\circ} \mathrm{C}$ for $\sim 3$ hours. The hydrogenation experiments were conducted at $150{ }^{\circ} \mathrm{C}$ for 5 or more hours starting with a $\sim 1.2 \times 10^{7} \mathrm{~Pa} \mathrm{H}_{2}$ gas overpressure.

\section{Modeling:}

The total energy calculations were carried out within the framework of generalized gradient approximation (GGA) (1) to density functional theory $(2,3)$ by using the projector augmented wave (PAW) method (4) as implemented in the Vienna Ab-initio Simulation Package (VASP) (5). The PAW potentials with the valence states $2 \mathrm{~s} 2 \mathrm{p}$ for C, $3 \mathrm{~s}$ for $\mathrm{Na}, 3 \mathrm{~s} 3 \mathrm{p}$ for $\mathrm{Al}$, and $1 \mathrm{~s}$ for $\mathrm{H}$ were employed. All results reported here have been successfully tested for convergence with respect to cutoff energy, k-points, and super-cell dimensions. Ionic positions and cell parameters were relaxed with respect to minimum forces and stress using conjugate-gradient algorithms. The ab initio molecular dynamics simulations were performed with the VASP code (5).

References for Supporting Information:

1. J. P. Perdew, J. A. Chevary, S. H. Vosko, K. A. Jackson, M. R. Pederson, D. J. Singh, C. Fiolhais, Phys. Rev. B 46, 6671 (1992).

2. P. Hohenberg, W. Kohn, Phys. Rev. 136, B864 (1964).

3. W. Kohn, L. J. Sham, Phys. Rev. 140, A1133 (1965).

4. P. E. Blöchl, Phys. Rev. B 50, 17953 (1994).

5. G. Kresse, J. Furthmüller, Phys. Rev B 54, 11169 (1996). 